Iberian Journal of the History of Economic Thought

ISSN-e 2386-5768

http://dx.doi.org/10.5209//JHE.58091

\title{
Vicent y Asturias
}

Joaquín Ocampo Suárez-Valdés ${ }^{1}$

Received: 01/11/2017 / Accepted: 10/11/2017

Resumen. Esta es una carta a Vicent Llombart de Joaquín Ocampo glosando su relación con Asturias.

Palabras clave: Vicent Llombart.

\section{[en] Vicent and Asturias}

Abstract. This is a letter from Joaquín Ocampo to Vicent Llombart giving account of his relationship with Asturias, Spain.

Keywords: Vicent Llombart

JEL Classification: B32.

Querido Vicent:

Somos lo que recordamos. Viene a cuento esta entrada por cuanto Pablo me ha pedido que ejercite la memoria para glosar tu relación con esta tierra a la que algún viajero ilustrado llamó "la Siberia del norte". Soy el peor escribiente de aquel quinteto - Álvaro Ruiz de la Peña, Inmaculada Urzainqui, Elena de Lorenzo, Lola Mateos y yo mismo- que, cual guardia pretoriana, velaba tus pasos y tu sombra cada vez que nos alegrabas con tus cortas y esperadas visitas a Oviedo.

¿Cuándo fue la primera vez que viniste? En 1976 leías tu tesis sobre Campomanes. A buen seguro que Ernest Lluch - pionero, con Gonzalo Anes y Miguel Artola, entre los miembros asociados que nutrieron las filas del Instituto Feijoo de Estudios del Siglo XVIII - te habría hablado de la conveniencia de visitar su biblioteca y fondos documentales. Resulta difícil precisar fechas, pero hay constancia de que visitaste el Instituto invitado por José Miguel Caso González en 1983, cuando Inmaculada y Álvaro publicaron su conocida monografía sobre Rubín de Celis. Aquel libro en que ellos le atribuían la paternidad del Discurso sobre el fomento de la industria popular, junto a la réplica que en 1990 dedicaste a "rehabilitar" a Campomanes como autor del Discurso, estuvieron en el origen de un fecundo intercambio intelectual y de una larga y hermosa amistad. En 1991 volviste a Asturias invitado por Enrique Fuentes Quintana para participar en los cursos de verano organizados en La Granda (Avilés) por la Escuela Asturiana de Estudios Hispánicos.

Y, ya desde 1999, fuiste invitado asiduo y casi imprescindible de los Cursos de Extensión Universitaria del Instituto Feijoo. Réplica de las universidades populares organizadas por los krausistas ovetenses (Sela, Buylla, Posada, Clarín...) a finales del siglo XIX, aquellos cursos dieciochistas reunían cada mes de julio, en Llanes o en Navia, a lo más granado del modernismo español y francés. A tales invitaciones académicas estivales pronto se añadirían tus visitas periódicas al Instituto y tu asistencia a congresos, seminarios y conferencias. Todas 
esas idas y venidas acabarían por acentuar tu "adicción asturiana" y por ensanchar el círculo de tus amigos "ilustrados".

Fue así como comenzaría a forjarse tu amistad con Elena de Lorenzo, actual directora del Instituto, y conmigo. También con otros profesores e investigadores - González Santos, Santos Coronas, Joaquín Varela, Ignacio Sarasola, Álvarez Antuña, Jaime Herrero... - y con algunos jóvenes por entonces alumnos de doctorado y becarios del Instituto: Juan Díaz, Noelia García y Juan Pablo Torrente Ballester - a quien, por olvidarte reiteradamente de su nombre, acabaste bautizando como "Juan, el de los lobos" por una tesis que le dirigía Gonzalo Anes sobre la caza en el Principado en el siglo XVIII.

Pero doy un paso más, pues no se trata aquí de detallar tu presencia académica en Asturias, por otro lado, recogida en detalle en la reseña bibliográfica que cierra este volumen. Y con ese paso mi única pretensión es la de rescatar, convocados por la memoria, los intangibles de nuestra amistad y de tus amistades asturianas. Y lo primero que debo recordarte es que tú has sido acreedor permanente de la reorientación de mi trayectoria investigadora. Cuando nos conocimos y me animaste a trabajar sobre Campomanes, te hice ver que mi ámbito de estudio era el de la historia de los hechos y no el de las ideas económicas. Insististe con un argumento que se probaría eficaz: entre los hechos y las ideas, decías, hay una frontera o tierra de nadie que espera ser explotada. Los historiadores de la economía, decías, acuden poco a la historia del pensamiento económico, y viceversa. A partir de ahí, y contando con tu insistencia, comenzaría una reconversión, aún inacabada, y cuyo fruto compartido sería el octavo volumen de las Obras completas de Jovellanos.

Pero mi trato contigo $-\mathrm{y}$ el editor me dirá si es canónico o conveniente entrar en este tipo de detalles - me deparó otros beneficios añadidos. De tu magisterio aprendí la importancia de los detalles y matices cuando se habla de las ideas económicas, de la necesidad de desechar esos tópicos tan al uso - Campomanes "buscador de rentas", Jovellanos "smithiano"... - bajo cuyo oropel se camuflan reiteraciones, simplificaciones y falta de estudio serio y documentado. También viví de cerca cómo tus "combates" por la ciencia y contra esas generalizaciones a que acabo de referirme, podían llegar a infligirte heridas disimuladas pero per- durables, máxime si alguna de los debatientes llevaba las desavenencias científicas al ámbito de lo personal. Y recuerdo igualmente tu complicidad - más o menos silenciosa - cuando te comentaba, no sin cierto asombro, las lecturas sesgadas y "territoriales" que desde ciertas periferias se hacían de Campomanes o de Jovellanos, y con las que, por cierto, nunca estuviste de acuerdo, aunque no llegases a manifestarlo por escrito debido a tu elegancia intelectual $\mathrm{y}$ al respeto que guardabas hacia quienes, por ausentes, ya no podían argumentar.

Tus conferencias y participaciones en los cursos de verano que compartimos, llamaban la atención por la calidad de la documentación que entregabas a los alumnos, por tu capacidad para aunar las exigencias divulgativas con el rigor académico. Podían versar sobre asuntos diversos, pero siempre flotaba en el aire la idea de que la Ilustración todavía tiene algo que decirnos. A veces - casi siempre-, tus charlas se interrumpían con prolongados silencios: te quedabas pensando, añadías un nuevo matiz obsesionado por que cada palabra o frase que pronunciabas fuese precisa y justificada. En muchos casos, te desviabas del río por el que fluía tu discurso para invitar a quienes te escuchaban a divisar otros paisajes, a navegar nuevos afluentes. Mientras, los minutos pasaban, y había que recordarte que hasta el tiempo tiene sus límites. Entonces sonreías, pedías perdón y añadías: "Bueno, habría mucho más que contar, por eso os he traído el dossier que os he entregado antes de comenzar...". Y, tras el obligado coloquio, siempre ofrecías tu correo para quienes quisieran disipar dudas o ampliar información.

Pero lo mejor de aquellos cursos y congresos eran, concluidas las tareas docentes, la posibilidad de compartir sobremesas, paseos, y charlas, sociabilidad. Entonces salía a relucir lo mejor y más divertido de nuestras poliédricas biografías. Era la academia al revés, porque, como sugirió W. Blake, "el camino del exceso conduce (a veces) al templo de la sabiduría". Tu tranquilo estoicismo, tu sedentarismo ilustrado, tu disposición festiva, tu afable conversación, la firmeza de tus convicciones, tu búsqueda del consenso frente al conflicto, formaban parte indeleble de aquellas tertulias.

Y cómo no recordarte en Sorribas (Tineo), contemplando con emoción la modesta casa natal de Campomanes; o en tus regresos de la obligada visita a la librería Ojanguren, de la que siempre volvías con cuatro o cinco "ki- 
los" de libros; o en tu último viaje a Gijón para la presentación de tu Jovellanos, el otoño de las luces.

En la terraza del hotel de Llanes, divisando el mar, o en la del Avenida, colgada sobre la ría de Navia, viendo anochecer, dejábamos arreglado el mundo hasta el día siguiente. Y al final, en el silencio que precede a la despedida y cuando ya todo estaba dicho, atesorábamos esos instantes sabiendo que todos nosotros, después, días o años después, tan solo seríamos lo que recordásemos.

\section{Bibliografía}

Llombart, V. (2008) Gaspar Melchor de Jovellanos. Obras Completas. Tomo X Escritos Económicos. Edición crítica, estudio preliminar, prólogo y notas de Vicente Llombart i Rosa y Joaquín Ocampo Suárez-Valdés. Gijón: Ayuntamiento de Gijón, Instituto Feijoo de Estudios del siglo XVIII, KRK Ed. - (2013) Jovellanos y el otoño de las Luces. Educación, economía, política y felicidad. Gijón: Trea. 